\title{
Stock Price Behavior of Nepalese Commercial Banks: Random Walk Hypothesis
}

\begin{abstract}
Using the data set on daily stock prices during the fiscal year 2015/16 (Sept 23, 2015 through Dec 22, 2015), this paper attempts to analyze the random behavior of stock price of Nepalese Commercial Banks by using run test, serial correlation and run tests and martingale random walk hypothesis under heteroscedasticity assumption of standard error. The results conclude that the proposition of Random Walk Hypothesis (RWH) in Nepalese stock markets does not hold true. This conclusion corroborates with the conclusions of the past studies carried out in Nepalese context.
\end{abstract}

Key Words: Efficient Market, Nepal, Random Walk. Stock Price Behavior Theories

\section{Introduction}

Financial sector has a crucial role to pool scattered savings for capital formation. Stock market in Nepalese financial market assists in mobilizing savings for economic sustainability. It allows the platform for the real sector growth which includes in the major infrastructural development of nation. But, the Nepalese securities market still is in growing stage. Its further development is crucial. In Nepal, the major constituent of the securities market is the shares of commercial banks and behavior of price of commercial banks influences the Nepal Stock Exchange index.

The studies on stock price behavior revealed a considerable interest in the long run time series properties of stock price, with a particular attention being paid to investigate whether stock prices characterized as random walk. If stock prices follow a mean reverting process then there exist a tendency for the price level to return to its trend path over time and investors may be able to forecast future returns by using information on its past returns. On the Contrary, a random walk process indicates that any shock to stock price is permanent and there is no tendency for the price level to return to a trend path over time.

Normally, the stock market index is taken as a barometer of an economy. Growth in stock index is normally considered as a good sign since it implies the investors are confident about the future prospect of the economy. It helps promote investment in the economy. However, a rapid increase in the stock market index is always a matter of concern. If the increase in the index is not justified by the fundamentals, such a rise cannot be sustained and eventually the index will plummet endangering the economic and financial stability.

Random walk hypothesis states that previous price changes or changes in return are useless in predicting future price or return changes. More precisely, this theory contends that successive price changes are independent and prices at any time, on the average, reflect the intrinsic value of security (Fischer \& Jordan, 2000). Random walks in stock returns are important for the formulation of rational expectations models and the testing of weakform market efficiency. Firstly, in an efficient market, prices of stocks fully incorporate all relevant information. Hence, stock returns will display unpredictable (or random walk) behavior. Secondly, the return generating process is dominated by a temporary component in stock prices those are not characterized by a random walk, and therefore, future returns can be predicted by the historical sequence of returns. Finally, the ability of stock markets to play the role that is usually ascribed to them - attracting foreign investment, boosting domestic saving

${ }^{1}$ Lecturer, School of Business, Pokhara University, Nepal,

${ }^{2}$ Associate Professor, School of Engineering, Pokhara University,

${ }^{3}$ Research Scholar, School of Business, Pokhara University, Nepal, 
and improving the pricing and availability of capital depends upon the presence of random walks.

Efficient-market hypothesis (EMH) states that it is impossible to "beat the market" because stock market efficiency causes existing share prices to always incorporate and reflect all relevant information. According to the EMH, stocks always trade at their fair value on stock exchanges, making it impossible for investors to either purchase undervalued stocks or sell stocks for inflated prices.

The accelerating pace of development of capital market in Nepal has opened the avenues for utilization of funds for corporate sectors. It is well accepted fact that Nepal has abundant resources, both human and natural, to exploit, but at the same it is facing inadequacy of financial resources. As the resource mobilization domestically as well as internationally is crucial for Nepal to speed up its economic development, it is essential that the stock market be efficient.

Nepal stock market has not been researched on the basis of book value of the company. The objective of the paper is to identify the behavior of the Nepalese commercial banks. The study findings are expected to serve investors for gaining profit and enable the policy makers to improve the level of efficiency. The absence and presence of the random walk in the price generation in the stock market is evaluated by using stock market indices of eight banks (Four banks have market share price less than Rs.1000 and four banks have above RS. 1000) from 22-Dec-2015 to 22-Mar-2016.

\section{Literature Review}

Oyama (1997), Policy Development and Review Development Division has conducted a study entitled on "Determinants of Stock Prices: The Case of Zimbabwe". The research study done by author focuses on the general relationship between stock prices and macroeconomics variables in Zimbabwe, using error-correction, model, the multi factor return - generating model. From the study author shows that despite the large fluctuation in stock prices since 1991, the analysis indicated that the
Zimbabwe Stock Exchange functioned quite consistently during that period.

Shubiri and Faris (2010) has conducted a study entitled on "Analysis of the Determinants of Market Stock Price Movements: An Empirical Study of Jordanian Commercial Banks". In the study, simple and multiple regression analysis is conducted to find out the relationship microeconomic factors with the stock price and found highly positive significant relationship between market price of stock and net asset value per share; market price of stock dividend percentage, gross domestic product, and negative significant relationship on inflation and lending interest rate but not always significant on some years of Amman Stock Exchange in Jordan.

Shrestha, (2014) has conducted a study entitled on: "Determinants of Stock Market Performance in Nepal". This research study empirically observes the determinants of the stock market performance in Nepal using monthly data for the period of mid-August 2000 to mid-July 2014. In the study, the impact of major changes in politics and Nepal Rastra Bank's policy on lending against share collateral has also been assessed. Empirical results obtained from OLS estimations of behavioral equations disclosed that the performance of stock market is found to respond positively to inflation and broad money growth, and negatively to interest rate.

Islam et al. (2015) has conducted a study entitled on "Determinants of Stock Price Movements": Evidence from Chittagong Stock Exchange, Bangladesh. The research focus on the incidents of 2010-2011 stock market crash in Bangladesh. The study aims to reexamine the relationship between stock price, dividend and retained earnings of 29 listed banks of Chittagong Stock Exchange, in the post-crash period. Cross-sectional data were collected from secondary sources. Using linear regression method, the study found that both, dividend and retained earnings of sample banks have strong influence over the stock price, though there was moderate explanatory power of those variables. This study concludes that both dividend and retained earnings are strong determinants of stock price at significant level. 
Baral et al. (2006) has conducted a study entitled on "Daily Stock Price Behavior of Commercial Banks in Nepal". The study conducted by the authors focuses to analyze the stock price behavior of commercial banks in Nepalese markets. To conduct the study the technical analysis and fundamental analysis is used. The study done by authors reveals that the observations of daily stock prices of sampled banks indicate that there is a large variation in their stock prices in the fiscal year 2005/06 which shows that banks are not doing well in Nepalese stock market. Also looking on the serial coefficients it can be stated that the values are significantly deviated from zero and statistically insignificant. It signifies that the successive price changes are dependent.

Pradhan et al. (2010) has conducted a study entitled on "Efficient market hypothesis and behavior of Share prices: the Nepalese evidence". The study conducted by authors' aims to assess equity share price behavior in Nepal and testing the hypothesis that share price changes are independent. In viewing the Auto-correlation test it shows that the random walk hypothesis is true for less frequently traded stocks and the same was not consistent with the prices of highly traded stocks. The study result also indicate that the random walk hypothesis is true for less frequently traded stocks and the same is not consistent with the prices of highly traded stocks.

Dangol (2010) has conducted a study entitled on "Testing Random-Walk Behavior in Nepalese Stock Market". The study conducted by author aim to measure the behavior of the stock returns in the Nepal Stock Exchange (NEPSE) using Augmented Dickey-Fuller (ADF) and Phillips-Perron (PP) unit root tests. The study of the author reveals that the random walk hypothesis for NEPSE index is rejected during the period of analysis. The Nepalese stock market is inefficient in daily returns series suggesting that past movements in stock prices can be used to predict their future movements.

\section{Data and Methodology}

\subsection{Data}

There are 231 companies which are listed in NEPSE as on $30^{\text {th }}$ March 2016. The sample firms among the listed companies selected for the study are A-class financial institutions. In this study, commercial bank represent the population and the number of the banks is 31 during the study period. Stratified sampling technique is used in which population is divided into homogenous groups (strata). Simply strata are designed on the basis of market price of share as: (i) MPS above Rs.1000 and

(ii) MPS below Rs.1000 and among them 8 commercial banks have been selected as a sample employing purposive sampling technique. The sample banks are as follows:

- MPS above Rs.1000

- Everest Bank Limited

- Nabil Bank Limited

- Nepal SBI Bank Limited

- Standard Chartered Bank Nepal Limited

- MPS below Rs.1000

- Kumari Bank Limited

- Laxmi Bank Limited

- Bank of Kathmandu

- Siddhartha Bank Limited

Closing daily share prices of above mentioned commercial banks during the study period covering three months from 23-Sep-2015 to 22-Dec-2015 are used as observations for the study.

\subsection{Research Methods}

Many statistical test are performed by the past research scholars to identify the random walk behavior of the stock price however following test are performed in this research.

\section{Runs Test}

Runs test is a non-parametric test that ignores the magnitude of price changes and observes only direction of changes in a given time series. For the present purpose, a run can be defined as a sequence of price changes of the same sign preceded and followed by price changes of different sign. For stock prices, there are three different possible types of price changes in a series, i.e., positive, negative and no-change, and thus three different types of runs. One sample runs test is a test used to judge the 
randomness of a sample on the basic of the order in which the observations are taken. The sampling distribution of ' $r$ ' statistic, the number of runs is to be used and this distribution has its mean and the standard deviation. Here the mean and standard error associated with the sampling distribution of $r$ which can be expressed as:

$\mu_{\mathrm{r}}=\left(2 \mathrm{n}_{1}{ }^{*} \mathrm{n}_{2} / \mathrm{n}_{1}+\mathrm{n}_{2}\right)+1$

$\mathrm{z}=\mathrm{r}-\mu / \sigma$

$\sigma_{\mathrm{r}}=\sqrt{2 \mathrm{n}_{1}{ }^{*} \mathrm{n}_{2}\left(2 \mathrm{n}_{1}{ }^{*} \mathrm{n}_{2}-\mathrm{n}_{1}-\mathrm{n}_{2}\right) /\left(\mathrm{n}_{1}+\mathrm{n}_{2}\right)^{2}\left(\mathrm{n}_{1}+\mathrm{n}_{2}-1\right)}$

Upper Limit: $\mu_{r}+z \sigma_{r}$, Lower Limit: $\mu_{r}-z \sigma_{r}$

\section{Autocorrelation Test}

It is now a common practice to treat the terms serial correlation and auto correlation synonymously (Gujarati, 2004). Serial correlation and auto correlation are considered synonymous. The autocorrelation coefficient $\left(\rho_{k}\right)$ provides a measure of the relationship between the value of a random variable in time ' $t$ ' and its value ' $\mathrm{k}$ ' periods earlier. In other words, it will indicate whether price changes at time ' $\mathrm{t}$ ' is influenced by the price changes occurring ' $k$ ' period earlier. A significant positive autocorrelation indicates the presence of trends. The presence of negative autocorrelation documents the existence of more reversals that might occur randomly. Numbers that are truly random will have zero serial correlation. For example, for the variable $\mu_{t}$, defined as the change in log price of a given security from the end of the day ' $t-1$ ' to the end of the day ' $t$ ', the autocorrelation coefficient for lag ' $\mathrm{k}$ ' is:

$r_{k}=\frac{\operatorname{Cov}\left(m_{t}, m_{t_{1} \cdot 1}\right)}{\operatorname{Var}\left(m_{t}\right)}$

\section{Box- Ljung test}

Ljung and Box (1978) develop the Box-Ljung test to examine the lack of fit of time series data, which define:

$\mathrm{H}_{\mathrm{o}}$ : Model doesn't exhibit lack of fit

$\mathrm{H}_{1}$ : Model exhibit the lack of fit

Test statistics is defined as

$$
Q=n(n+2) \sum_{k=1}^{m} \frac{\hat{r}_{k}{ }_{k}}{n-k}
$$

Where $r^{\wedge} k$ estimated autocorrelation of the series at lag $\mathrm{k}$ and $\mathrm{m}$ is the number of lags being tested

\section{Martingale Random Walk Hypothesis}

According to Arlt and Arltová (2000), martingale model belongs to the earliest models of the financial asset prices. Its origin lies in the birth of the probability theory and the historic of game of chance. It follows a principle of a fair game i.e. the game neither in your favor nor your pennant's. Martingale is a stochastic process $\left\{\mathrm{P}_{\mathrm{t}}\right\}$ which satisfied following condition:

$\mathrm{E}\left[\mathrm{P}_{\mathrm{t}} / \mathrm{P}_{\mathrm{t}-1}, \mathrm{P}_{\mathrm{t}-2}, \ldots\right]=\mathrm{P}_{\mathrm{t}}$

Equivalently, it is possible to write

$\mathrm{E}\left[\mathrm{P}_{\mathrm{t}}-\mathrm{P}_{\mathrm{t}-1} / \mathrm{P}_{\mathrm{t}-1}, \mathrm{P}_{\mathrm{t}-2}, \ldots\right]=0$...

If $\mathrm{P}_{\mathrm{t}}$ is the asset's price at time $\mathrm{t}$, the martingale hypothesis means that tomorrow's price is expected to be equal to today's price under the condition of the entire history development of the asset's price. The forecasting meaning follows: the martingale hypothesis implies that the "best" forecast (from the point of view of mean square error) of tomorrow's price is simply today's price.

Historically, the martingale is closely related to hypothesis of efficient market which means that the information contained in past asset's prices is completely reflected in the current price. In efficient market it is not possible to profit by trading on the information contained in the asset's price history. Despite the fact that the modern financial economics considers the necessity of some trade-off between risk and expected returns, martingale is still powerful tool and has important applications in theory of asset prices. Another aspect of martingale is that it is basis for the development of a closely related model which is called random walk.

Lo and Mickinly (1988) develop the special approach of variance ratio test for the null hypothesis of a martingale, which is robust to heteroskedastic standard errors. The time series follows a random walk then the variance should be proportional of the some interval, i.e

$\operatorname{VR}(q)=\frac{\operatorname{Var}\left(Y_{t+k}-Y_{t}\right) / k}{\operatorname{Var}\left(Y_{t+1}-Y_{t}\right)}$

The statistical test is given as

$$
Z_{1}(q)=\frac{V R(q)-1}{\sqrt{\phi(q)}}
$$


where $\phi(q)=\frac{2(2 q-1)(k-1)}{3 q T}$

Which follows an asymptotically $\mathrm{N}(0,1)$ distribution, under the homoscedasticity assumption.

The statistical test which is robust under heteroscedasticity is given as follows

$$
\overline{V R}(q)={ }_{z} 1+2 \sum_{k=1}^{q-1}\left(1-\frac{k}{q}\right) \hat{\rho}(k)
$$

where "=" means asymptotically equals. They supposed $^{\mathrm{a}}$ that $\hat{\rho}(k)$ are asymptotically uncorrelated. The asymptotic variance $\theta(\mathrm{q})$ of $\overline{V R}(q)$ can be calculated as the weighted sum of $\delta_{\mathrm{k}}$ 's, which are the asymptotic variances of autocorrelations $\overline{V R}(q)$. Lo and MacKinley (1988) showed that

(a) The statistics $\overline{V R}(q)-1$ converges surely to zero for all a as $\mathrm{n}$ increases without bound

(b)

$$
\hat{\delta}_{k}=\frac{n q \sum_{j=k+1}^{n q}\left(P_{j}-P_{j-1}-\hat{c}\right)^{2}\left(P_{j-k}-P_{j-k-1}-\hat{c}\right)^{2}}{\left[\sum_{j=1}^{n q}\left(P_{j}-P_{j-1}-\hat{c}\right)^{2}\right]^{2}}
$$

Is a heterocedasticity-consistent estimator $\hat{\delta}_{k}$

(c) Heteroscedasticity-consistent estimator $\mathrm{q}(q)$ has

$$
\text { form } \hat{\theta}(q)=4 \sum_{k=1}^{q-1}\left(1-\frac{k}{q}\right)^{2} \delta_{k}^{2}
$$

The following standardized test statistic for testing of the null hypothesis $\mathrm{Ho}^{*}$ can be used

$$
Z^{*}(q)=\frac{\sqrt{n q(\overline{V R}(q)-1)}}{\sqrt{\hat{\theta}(q)}}
$$

Chow and Denning (1993) extend the Variation ratio test by introducing multiple variation ratio test which is based on the maximum absolute value of individual variation ratio test

$$
Z_{2}(q)=\max _{1 \leq i \leq N}\left|Z_{q_{i}}^{*}\right|
$$

Thus, in very simple terms, what Lo and MacKinlay do is test the null hypothesis that a time series has the property that

$$
\operatorname{VR}(q)=\frac{\operatorname{Var}\left(Y_{t+k}-Y_{t}\right) / k}{\operatorname{Var}\left(Y_{t+1}-Y_{t}\right)}=1
$$

If we cannot reject the null hypothesis that the "variance ratio' is equal to 1 , then we can say that the series follows

\begin{tabular}{|c|c|c|c|c|}
\hline Test Parameters & BOK & LBL & KBL & SBL \\
\hline $\begin{array}{l}\text { Test Value } \\
\text { ( Median) }\end{array}$ & 588 & 590 & 484 & 627 \\
\hline N1 (< test value) & 44 & 39 & 43 & 46 \\
\hline $\mathrm{N} 2(>=$ test value $)$ & 48 & 53 & 49 & 46 \\
\hline $\begin{array}{l}\text { N (total } \\
\text { observations) }\end{array}$ & 92 & 92 & 92 & 92 \\
\hline No of runs (r) & 39 & 32 & 22 & 10 \\
\hline Lower Limit & 34.6292 & 33.9131 & 34.5526 & 34.6949 \\
\hline Upper Limit & 59.1908 & 57.9468 & 59.0569 & 59.3050 \\
\hline Z value & -1.662 & -2.992 & -5.223 & -7.758 \\
\hline $\begin{array}{l}\text { Asymp. Sig } \\
\text { (2-tailed) }\end{array}$ & 0.096 & 0.003 & 0.000 & 0.000 \\
\hline
\end{tabular}
a random walk. If we can reject the null, then we can reject the idea that the series is a random walk.

\section{Empirical Analysis \\ Run test for MPS below Rs. 1000}

Table I: Run-test for MPS below Rs. 1000

In above run test analysis for BOK, the table exhibits shows that median value is 588 . Out of the 92 total cases in daily stock price returns 44 cases are below the median whereas 48 cases are above or equal to the median also the number of run is 39. The table also exhibits on the range of lower and upper limits. The lower limit is 34.6292 and upper limit is 59.1908 which state that the no of runs need to be within this range for null hypothesis to be accepted and here the no of runs lies in between limits as it lies in rejection region, $\mathrm{z}$ value is also less than -1.96 and also asymptotic sig (2-tailed) value is 0.096 which seems above 0.01 so $\mathrm{H}_{0}$ is accepted stating that stock price behavior are random.

In above run test analysis for LBL, the table exhibits shows that median value is 590 . Out of the 92 total cases in daily stock price returns 39 cases are below the median whereas 53 cases are above or equal to the median also the number of run is 32 . The lower limit is 33.9131 and upper limit is 57.9468 , here the no of runs does not lies in between limits, $\mathrm{z}$ value is also greater than -1.96 and asymptotic sig (2-tailed) value is 0.003 which is less than 0.01 so $\mathrm{H}_{0}$ is rejected and alternative hypothesis is accepted stating that stock price behavior are not random.

In above run test analysis for KBL, the table exhibits shows that median value is 484 . Out of the 92 total cases in daily stock price returns 43 cases are below the median whereas 49 cases are above or equal to the median also the number of run is 22 . The lower limit is 34.5526 and upper limit is 59.0569 , here the no of runs does not lies 
in between limits as it lies in rejection region $\mathrm{z}$ value is also greater than -1.96 and asymptotic sig (2-tailed) value is 0.000 which is less than 0.01 so $\mathrm{H}_{0}$ is rejected and alternative hypothesis is accepted stating that stock price behavior are not random.

In above run test analysis for SBL, the table exhibits shows that median value is 627 . Out of the 92 total cases in daily stock price returns 46 cases are below the median whereas 46 cases are above or equal to the median also the number of run is 10 . The table also exhibits on the range of lower and upper limits. The lower limit is 34.6949 and upper limit is 59.3050 , here the no of runs does not lies in between limits as it lies in rejection region, $\mathrm{z}$ value is also greater than -1.96 and asymptotic sig (2-tailed) value is 0.000 which is less than 0.01 so $\mathrm{H}_{0}$ is rejected and alternative hypothesis is accepted stating that stock price behavior are not random.

\section{Run test for MPS above Rs. 1000}

Table II: Run-test for MPS above Rs. 1000

\begin{tabular}{lcccc}
\hline Test Parameters & SCBNL & EBL & NABIL & NSBI \\
\hline $\begin{array}{l}\text { Test Value( Me- } \\
\text { dian) }\end{array}$ & 2674 & 2355 & 1899 & 1439 \\
N1 (< test value) & 45 & 43 & 46 & 46 \\
N2 (>= test & 47 & 49 & 46 & 46 \\
value) & & & & \\
N (total observa- & 92 & 92 & 92 & 92 \\
tions) & 18 & 18 & 6 & 10 \\
No of runs (r) & 33.7008 & 34.5526 & 34.6949 & 34.6949 \\
Lower Limit & 58.299 & 59.0569 & 59.3050 & 59.3050 \\
Upper Limit & -6.079 & -6.065 & -8.596 & -7.758 \\
$\begin{array}{l}\text { Z value } \\
\text { Asymp. Sig }\end{array}$ & 0.000 & 0.000 & 0.000 & 0.000 \\
(2-tailed) & & & & \\
\hline
\end{tabular}

In above run test analysis for SCBNL, the table exhibits shows that median value is 2674 . Out of the 92 total cases in daily stock price returns 45 cases are below the median whereas 47 cases are above or equal to the median also the number of run is 18 . The table also exhibits on the range of lower and upper limits. The lower limit is 33.7008 and upper limit is 58.299 , here the no of runs does not lies in between limits as it lies in rejection region $\mathrm{z}$ value is also greater than -1.96 and asymptotic sig (2-tailed) value is 0.000 which is less than 0.01 so $\mathrm{H}_{0}$ is rejected.

In above run test analysis for EBL, the table exhibits shows that median value is 2355 . Out of the 92 total cases in daily stock price returns 43 cases are below the median whereas 49 cases are above or equal to the median also the number of run is 18 . The table also exhibits on the range of lower and upper limits. The lower limit is 34.5526 and upper limit is 59.0569 , here the no of runs does not lies in between limits as it lies in rejection region $\mathrm{z}$ value is also greater than -1.96 and asymptotic sig (2-tailed) value is 0.000 which is less than 0.01 so $\mathrm{H}_{0}$ is rejected.

In above run test analysis for NABIL, the table exhibits shows that median value is 1899 . Out of the 92 total cases in daily stock price returns 46 cases are below the median whereas 46 cases are above or equal to the median also the number of run is 6 . The lower limit is 34.6949 and upper limit is 59.3050 , here the no of runs does not lies in between limits, $\mathrm{z}$ value is also greater than -1.96 and asymptotic sig (2-tailed) value is 0.000 which is less than 0.01 so $\mathrm{H}_{0}$ is rejected.

In above run test analysis for NSBI, the table exhibits shows that median value is 1439 . Out of the 92 total cases in daily stock price returns 46 cases are below the median whereas 46 cases are above or equal to the median also the number of run is 10 . The lower limit is 34.6949 and upper limit is 59.3050 , here the no of runs does not lies in between limits, $\mathrm{z}$ value is also greater than -1.96 and asymptotic sig (2-tailed) value is 0.000 which is less than 0.01 so $\mathrm{H}_{0}$ is rejected.

Run test for overall sampled banks

Table III: Run-test for Overall Sampled Banks

\begin{tabular}{lc}
\hline \multicolumn{1}{c}{ Test Parameters } & Data's \\
\hline Test Value( Median) & 1326.063 \\
N1 (< test value) & 46 \\
N2 (>= test value) & 46 \\
N (total observations) & 92 \\
No of runs (r) & 8 \\
Lower Limit & 34.6949 \\
Upper Limit & 59.3050 \\
Z value & -8.177 \\
Asymp. Sig (2-tailed) & 0.000
\end{tabular}

In above run test analysis for overall Sampled Banks, the table exhibits shows that median value is 1326.063 . Out 
of the 92 total cases in daily stock price returns 46 cases are below the median whereas 46 cases are above or equal to the median also the number of run is 8 . The table also exhibits on the range of lower and upper limits. The lower limit is 34.6949 and upper limit is 59.3050, here the no of runs does not lies in between limits as it lies in rejection region, $\mathrm{z}$ value is also greater than -1.96 and asymptotic sig (2-tailed) value is 0.000 which is less than 0.01 so $\mathrm{H}_{0}$ is rejected stating that stock price behavior are not random.

\section{Serial Correlation Analysis}

\section{Serial Correlation MPS below Rs. 1000}

In serial correlation, different data's were exhibited as ACF (autocorrelation function), auto-correlation coefficient, standard error, box L-jung statistics and significance level of each of the banks having MPS < Rs1000 were presented. While analysis 16 lags period is observed. The auto-correlation coefficient includes both positive and negative valued data. Since all significance values in box L-jung statistics are below 0.05 level of significance so this results shows that stock price of banks having MPS below Rs. 1000 are of non-random nature.

\section{Serial Correlation for MPS above Rs. 1000}

In serial correlation, different data's were exhibited as ACF (autocorrelation function), auto-correlation coefficient, standard error, box L-jung statistics and significance level of each of the banks having MPS > Rs1000 were presented. While analysis 16 lags period is observed. The auto-correlation coefficient includes both positive and negative valued data. Since all significance values in box L-jung statistics are below 0.05 level of significance so this results shows that stock price of banks having MPS above Rs.1000 are of non-random nature. The results are shown in Appendix II.

\section{Serial Correlation for Overall Sampled Banks}

In serial correlation, different data's were exhibited as ACF (autocorrelation function), auto-correlation coefficient, standard error, box L-jung statistics and significance level of each of the sampled banks were presented. While analysis 16 lags period is observed. The auto-correlation coefficient includes both positive and negative valued data. Since all significance values in box L-jung statistics fall below 5\% level of significance so that stock price of overall sampled banks in aggregate are of non-random nature.

\section{Martingale Variance Ratio Test}

Table IV : Martingale Variance Ratio Test of Bank having Book Value Rs. $(<1000)$

\begin{tabular}{|c|c|c|c|c|c|c|c|}
\hline \multicolumn{4}{|c|}{$\begin{array}{l}\mathrm{H}_{0}: \text { First Lag of Laxmi Bank is Martingale } \\
\text { Heteroskedasticity robust standard error estimates }\end{array}$} & \multicolumn{4}{|c|}{$\begin{array}{l}\mathrm{H}_{\mathrm{o}} \text { : First Lag of Bank of Kathmandu is Martingale } \\
\text { Heteroskedasticity robust standard error estimates }\end{array}$} \\
\hline Joint Tests & & Value $\quad \mathrm{df}$ & Probability & Joint Tests & Value & $\mathrm{df}$ & Probability \\
\hline $\operatorname{Max}|z|($ at period 2)* & & 3.38846890 & 0.0028 & $\operatorname{Max}|z|$ (at & period 4)*2.778093 & 91 & 0.0217 \\
\hline Individual Tests & & & & Individual & Tests & & \\
\hline Period & Var. Ratio & Std. Error z-Statistic & Probability & Period & Var. RatioStd. Error & rz-Statistic & cProbability \\
\hline 2 & 0.442482 & $0.164534-3.38847$ & 0.0007 & 2 & 0.7653240 .128664 & -1.82395 & 0.0682 \\
\hline 4 & 0.279876 & $0.265641-2.71089$ & 0.0067 & 4 & $\begin{array}{ll}0.39081 & 0.219283\end{array}$ & -2.77809 & 0.0055 \\
\hline 8 & 0.133181 & $0.377002-2.29924$ & 0.0215 & 8 & 0.2379270 .321737 & -2.36862 & 0.0179 \\
\hline 16 & 0.060302 & $0.516398-1.81972$ & 0.0688 & 16 & 0.1239510 .446628 & -1.96148 & 0.0498 \\
\hline \multicolumn{4}{|c|}{$\begin{array}{l}\mathrm{H}_{0} \text { : First Lag of Kumari Bank is Random } \\
\text { Standard error estimates assume no heteroskedasticity }\end{array}$} & \multicolumn{4}{|c|}{$\begin{array}{l}\mathrm{H}_{\mathrm{o}} \text { : First Lag of KUMARI Bank is a martingale } \\
\text { Heteroskedasticity robust standard error estimates }\end{array}$} \\
\hline Joint Tests & & Value $\quad \mathrm{df}$ & Probability & Joint Tests & Value & df & Probability \\
\hline $\operatorname{Max}|z|($ at period 2)* & & 5.34116490 & 0 & $\operatorname{Max}|z|$ (at & period 2)* 1.948862 & 90 & 0.19 \\
\hline Wald (Chi-Square) & & 28.944464 & 0 & Individual & Tests & & \\
\hline Individual Tests & & & & Period & Var. RatioStd. Error & rz-Statistic & cProbability \\
\hline Period & Var. Ratio & Std. Error z-Statistic & Probability & 2 & $\begin{array}{lll}0.436992 & 0.288891\end{array}$ & -1.94886 & 0.0513 \\
\hline 2 & 0.436992 & $0.105409-5.34116$ & 0 & 4 & 0.2298450 .452099 & -1.70351 & 0.0885 \\
\hline 4 & 0.229845 & $0.197203-3.9054$ & 0.0001 & 8 & 0.1359240 .570213 & -1.51536 & 0.1297 \\
\hline 8 & 0.135924 & $0.311805-2.77121$ & 0.0056 & 16 & 0.0602140 .668967 & -1.40483 & 0.1601 \\
\hline 16 & 0.060214 & $0.46398-2.02549$ & 0.0428 & & & & \\
\hline
\end{tabular}


$\mathrm{H}_{\mathrm{o}}$ : First lag of Siddharth Bank is a martingale

Heteroskedasticity robust standard error estimates

Joint Tests

$\operatorname{Max}|z|($ at period 2)*

Value df
Individual Tests

Period Var. Ratio Std. Error z-Statistic Probability

$\begin{array}{lllll}2 & 0.485789 & 0.144412 & -3.56073 & 0.0004\end{array}$

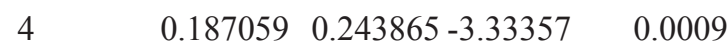

$\begin{array}{lllll}8 & 0.112023 & 0.345209 & -2.57229 & 0.0101\end{array}$

16

$\begin{array}{lll}0.054817 & 0.462005-2.04583 & 0.0408\end{array}$

Above table indicates that the stock price behavior of the entire sample bank doesn't follow the martingale random walk. However the Kumari Bank Limited, Standard Chartered Bank and Nepal SBI Bank follow martingale random walk under the assumption of heteroskedasticity robust standard error estimates but it is not supported by random walk hypothesis under the assumption of homoscedasticity. Where, the examination was based on one lag difference as a result data were free from non-stationary problem. Chian et al. (2000) analyzing stock returns for a group of Asian economies find that most markets exhibit an autoregressive process rejecting weak form efficiency, retrieved from Cooray \& Wickremasinghe (2007). Ahmed(2002) also examine the efficiency in the stock market, found that stock price of Dhaka can't be described by the random walk hypothesis. Balsara et.al (2007) found that, Chinese stock market doesn't corroborate the random walk hypothesis.

So it can infer from these studies that emerging markets like Nepalese stock market doesn't support random walk behavior. It should be because of immaturity of the market. Seasonality or lack of secrecy of the top management can be the cause of predictable behavior of the price. However, it would be the future researchable issue. Due to aforementioned fact stock price of behavior of Nepalese commercial bank is not random.

\section{Conclusion}

Observations of daily stock prices of sampled banks indicate that there is a consistent variation in some bank and small variation in their stock prices in some banks but they are showing normal distribution pattern in their stock price behavior. In serial coefficients, all significance values in box L-jung statistics (based on asymptotic chi-square approximation) signify that the successive price changes are dependent. Therefore, the Nepalese stock market is inefficient in pricing the shares. Runs test results also show that the percentage of deviation between the observed and actual number of runs in the series of price changes is significant. Martingale random walk hypothesis also support the box L-jung statistics and run test. To conclude, pricing behavior of Nepalese commercial bank is predictable or nonrandom. As the results indicate, the Nepalese stock market is not efficient even in the weak form which reveals that the informational efficiency of the market needs to be improved. Hence, stock market regulators and policymakers should focus on enhancing efficiency of the market. Investors can benefit from non-random behavior of the stock prices to make informed forecasts of the stock prices and earn superior investment return. However, the results are based on daily price of only eight sample firms from financial industry covering three months only. Future studies can be conducted using larger sample units including firms from other sectors in order to improve generalizability of the study results. Building on the study findings which indicate that stock prices in Nepal are non random and predictable, further studies aiming in developing stock price forecasting models are interesting vein for future research. Furthermore, employing event study methodology or neural network to ascertain stock price behavior of the Nepalese stock market is a new direction for future research in the area.

\section{References}

Arlt, J. \& Arltová, M.(2000). Variance Ratios, SocioEconomical Applications of Statistical Methods, Wroclaw University of Economics Publishing House, 2000. ISBN 83-7011-453-9.
Ahmed, M.F.(2002). Market Efficiency in Emerging Stock Markets: The Case of Dhaka Stock Exchange Savings and Development, 26 (1), 49-68. 
Balsara, N.J., Chen G., \& Zheng L.(2007). The Chinese Stock Market: An Examination of the Random Walk Model and Technical Trading Rules. Quarterly Journal of Business and Economics, Vol. 46(2), 43-63.

Baral,K.J.\& Shrestha, S.K.(2006) Daily Stock Price Behavior of Commercial Banks Banks in Nepal. The Journal of Nepalese Business Studies, 1, $1-11$.

Chiang T. C, Yang, S. Y. \& Wang T. S. (2000). Stock Return and Exchange Rate Risk: Evidence from Asian Stock Markets Based on a Bivariate GARCH Model. International Journal of Business 2, 97-1

Chow, K.V. \& Denning. K.C. (1993). A simple multiple variance ratio test. Journal of Econometrics $, 58,385-401$.

Cooray, A \& Wickremasinghe, G.(2007). The Efficiency of Emerging Stock Markets: Empirical Evidence from the South Asian Region. The Journal of Developing Areas, 41, (1), 171-183.

Dangol, J (2010) "Testing Random-Walk Behavior in Nepalese Stock Market". PYC Nepal Journal of Management, 1, 28-36

Horne, V \& Wachowicz,(2000), "Investments. New Delhi: Prentice Hall of India Pvt. Ltd

Islam, Syedul.M. \& Dooty. Nusrat, E.( 2015) .Determinants of Stock Price Movements: Evidence from Chittagong Stock Exchange, Bangladesh. Journal of Economics and Business Research, 2, 117-133.

Ljung G \& Box G (1978) . On a Measure of Lack of Fit in
Time Series Models, Biometrika, 65, 297-303

Oyama, T (1997). Determinants of Stock Prices: The Case of Zimbabwe.

Pradhan, R.S. \& Saraswati, KC (2010) Efficient market hypothesis and behavior of Share prices:the Nepalese evidence, SEBO Journal Vol. IV,104117

Shrestha,K. P \& Subedi, B.R. (2014) Determinants of Stock Market Performance in Nepal. NRB Economic Review, 25-40.

Shrestha,K. P \& Subedi, B.R. (2014) Determinants of Stock Market Performance in Nepal. NRB Economic Review, 25-40.

Shubiri, Faris N.(2010).Analysis the Determinants of Market Stock Price Movements: An Empirical Study of Jordanian Commercial Banks. International Journal of Business and Management , 5(10),1-11.

Walter, J. E. (1963) . Dividend Policy: Its influence on the Value of Enterprise, Journal of Finance, XXXI, 280-291.

Weston, J.F. \& Brigham, E. F. $\quad\left(\begin{array}{llll}1 & 9 & 8 & 7\end{array}\right)$. Essentials of Managerial Finance. Chicago: The Dryden Press.

Weston, B. and Brigham, E. F (1995). Essentials of Managerial Finance. New Delhi: Prentice Hall of India Pvt. Ltd.

Zahir, K \& Shah, M. (1982). Issues of Book Value Per Share and its Impacts on BFI's .Journal of Finance, XXXI, 280-291. 


\section{Appendix I}

\section{Serial Correlation of Daily Closing Stock Prices}

Series: Bank of Kathmandu (BOK)

\begin{tabular}{cccccc}
\hline \multirow{2}{*}{ Lag } & \multirow{2}{*}{$\begin{array}{c}\text { Auto } \\
\text { correlation }\end{array}$} & \multirow{2}{*}{ Std. Errora } & \multicolumn{3}{c}{ Box-Ljung Statistic } \\
\cline { 4 - 6 } & .467 & .103 & Value & df & Sig.b \\
\hline 1 & .168 & .102 & 23.682 & 1 & .000 \\
2 & .063 & .101 & 23.773 & 3 & .000 \\
3 & .063 & .101 & 24.625 & 4 & .000 \\
4 & .093 & .100 & 25.980 & 5 & .000 \\
5 & .117 & .097 & 27.828 & 10 & .002 \\
10 & -.031 & .094 & 32.413 & 15 & .006 \\
15 & -.061 & & & & \\
\hline
\end{tabular}

(Series: Laxmi Bank Limited (LBL

\begin{tabular}{cccccc}
\hline \multirow{2}{*}{ Lag } & Auto & \multirow{2}{*}{ Std. Errora } & \multicolumn{3}{c}{ Box-Ljung Statistic } \\
\cline { 4 - 6 } & correlation & & Value & df & Sig.b \\
\hline 1 & .637 & .103 & 38.577 & 1 & .000 \\
2 & .379 & .102 & 52.392 & 2 & .000 \\
3 & .078 & .101 & 52.990 & 3 & .000 \\
4 & -.063 & .101 & 53.380 & 4 & .000 \\
5 & -.024 & .100 & 53.438 & 5 & .000 \\
10 & -.167 & .097 & 62.404 & 10 & .000 \\
15 & .216 & .094 & 81.813 & 15 & .000 \\
\hline
\end{tabular}

Series: Kumari Bank Limited (KBL)

\begin{tabular}{cccccc}
\hline \multirow{2}{*}{ Lag } & Auto & Std. Er- & \multicolumn{3}{c}{ Box-Ljung Statistic } \\
\cline { 4 - 6 } & correlation & rora & Value & df & Sig.b \\
\hline 1 & .922 & .103 & 80.756 & 1 & .000 \\
2 & .863 & .102 & 152.390 & 2 & .000 \\
3 & .805 & .101 & 215.409 & 3 & .000 \\
4 & .763 & .101 & 272.632 & 4 & .000 \\
5 & .734 & .100 & 326.197 & 5 & .000 \\
10 & .540 & .097 & 520.810 & 10 & .000 \\
15 & .386 & .094 & 632.531 & 15 & .000 \\
\hline
\end{tabular}

Series: Siddhattha Bank Limited (SBL)

\begin{tabular}{cccccc}
\hline \multirow{2}{*}{ Lag } & \multirow{2}{*}{$\begin{array}{c}\text { Auto } \\
\text { correlation }\end{array}$} & Std. & \multicolumn{3}{c}{ Box-Ljung Statistic } \\
\cline { 4 - 6 } & Errora & & Value & df & Sig.b \\
\hline 1 & .867 & .103 & 71.356 & 1 & .000 \\
2 & .798 & .102 & 132.559 & 2 & .000 \\
3 & .745 & .101 & 186.558 & 3 & .000 \\
4 & .678 & .101 & 231.722 & 4 & .000 \\
5 & .631 & .100 & 271.263 & 5 & .000 \\
10 & .245 & .097 & 359.812 & 10 & .000 \\
15 & -.027 & .094 & 367.260 & 15 & .000 \\
\hline
\end{tabular}

Series: Standard Chartered Bank

\begin{tabular}{cccccc}
\hline \multirow{2}{*}{ Lag } & Auto & Std. & \multicolumn{3}{c}{ Box-Ljung Statistic } \\
\cline { 4 - 6 } & correlation & Errora & Value & df & Sig.b \\
\hline 1 & .883 & .103 & 74.174 & 1 & .000 \\
2 & .762 & .102 & 130.025 & 2 & .000 \\
3 & .661 & .101 & 172.512 & 3 & .000 \\
4 & .573 & .101 & 204.731 & 4 & .000 \\
5 & .551 & .100 & 234.912 & 5 & .000 \\
10 & .377 & .097 & 335.778 & 10 & .000 \\
15 & .232 & .094 & 374.701 & 15 & .000 \\
\hline
\end{tabular}

Series: Everest Bank limited

\begin{tabular}{cccccc}
\hline \multirow{2}{*}{ Lag } & \multirow{2}{*}{$\begin{array}{c}\text { Auto } \\
\text { correlation }\end{array}$} & \multirow{2}{*}{ Std. Errora } & \multicolumn{3}{c}{ Box-Ljung Statistic } \\
\cline { 4 - 6 } & .942 & .103 & 84.413 & 1 & .000 \\
1 & .888 & .102 & 160.177 & 2 & .000 \\
2 & .838 & .101 & 228.371 & 3 & .000 \\
3 & .838 & .101 & 289.564 & 4 & .000 \\
4 & .789 & .100 & 344.677 & 5 & .000 \\
5 & .745 & .097 & 535.189 & 10 & .000 \\
10 & .509 & .090 & Sig.b \\
15 & .281 & .094 & 611.219 & 15 & .000 \\
\hline
\end{tabular}

\section{Series: Nabil Bank Limited}

\begin{tabular}{cccccc}
\hline \multirow{2}{*}{ Lag } & \multirow{2}{*}{$\begin{array}{c}\text { Auto } \\
\text { correlation }\end{array}$} & \multirow{2}{*}{ Std. Errora } & \multicolumn{3}{c}{ Box-Ljung Statistic } \\
\cline { 4 - 6 } & .844 & .103 & 67.616 & 1 & .000 \\
\hline 1 & .755 & .102 & 122.372 & 2 & .000 \\
2 & .685 & .101 & 168.016 & 3 & .000 \\
3 & .685 & .101 & 205.042 & 4 & .000 \\
4 & .614 & .100 & 237.459 & 5 & .000 \\
5 & .571 & .097 & 325.400 & 10 & .000 \\
10 & .307 & .094 & 369.561 & 15 & .000 \\
15 & .276 & .06 &
\end{tabular}

\section{Series: Nepal SBI bank Limited}

\begin{tabular}{llllll}
\hline \multirow{2}{*}{ Lag } & $\begin{array}{l}\text { Auto } \\
\text { correlation }\end{array}$ & Std. Errora & \multicolumn{3}{l}{ Box-Ljung Statistic } \\
\cline { 5 - 6 } & & Value & df & Sig.b \\
\hline 1 & .836 & .103 & 66.390 & 1 & .000 \\
2 & .727 & .102 & 117.169 & 2 & .000 \\
3 & .637 & .101 & 156.627 & 3 & .000 \\
4 & .533 & .101 & 184.556 & 4 & .000 \\
5 & .447 & .100 & 204.410 & 5 & .000 \\
10 & .204 & .097 & 253.122 & 10 & .000 \\
15 & .016 & .094 & 255.814 & 15 & .000 \\
\hline
\end{tabular}


Series: Average Value

\begin{tabular}{cccccc}
\hline \multirow{2}{*}{ Lag } & \multirow{2}{*}{$\begin{array}{c}\text { Auto } \\
\text { correlation }\end{array}$} & Std. Errora & \multicolumn{3}{c}{ Box-Ljung Statistic } \\
\cline { 3 - 5 } & .896 & .103 & 76.246 & df & Sig.b \\
\hline 1 & .790 & .102 & 136.182 & 2 & .000 \\
2 & .690 & .101 & 182.402 & 3 & .000 \\
3 & .595 & .101 & 217.228 & 4 & .000 \\
4 & .541 & .100 & 246.282 & 5 & .000 \\
5 & .357 & .097 & 332.815 & 10 & .000 \\
10 & .299 & .094 & 386.372 & 15 & .000 \\
15 & &
\end{tabular}

Appendix II

Martingale variance ratio test of bank having book value RS.(>1000)

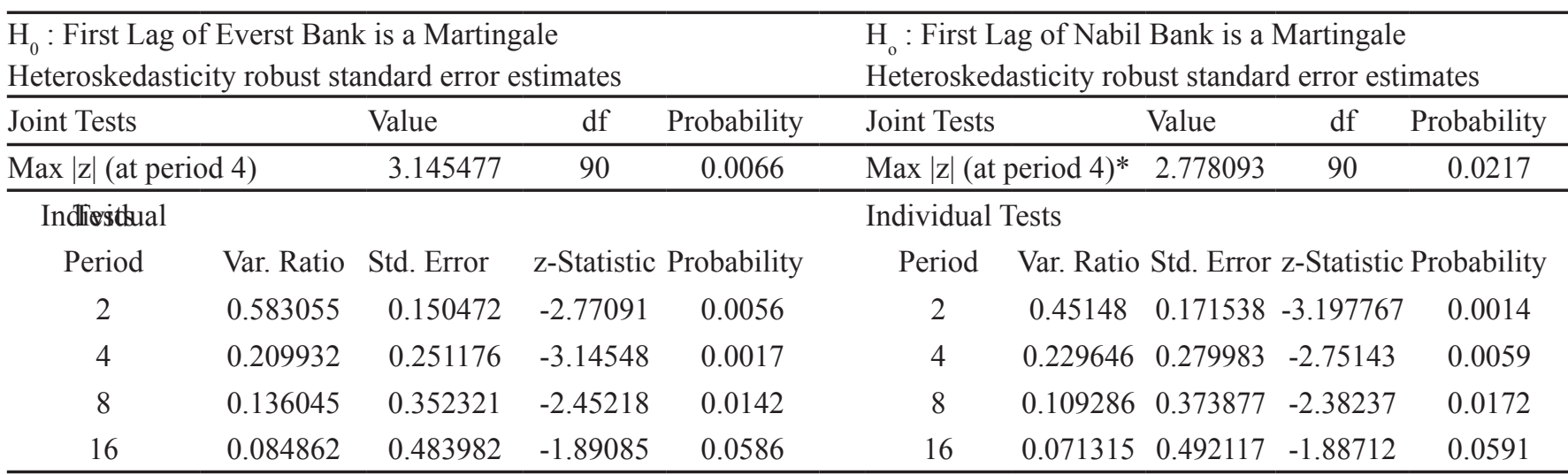

Null Hypothesis: Log of SBI Bank is a Martingale

Heteroskedasticity robust standard error estimates

Null Hypothesis: DSBI is a Random Walk

\begin{tabular}{|c|c|c|c|c|c|c|c|c|c|}
\hline \multicolumn{2}{|l|}{ Joint Tests } & Value & df & Probability & \multicolumn{2}{|c|}{ Joint Tests } & Value & $\mathrm{df}$ & Probability \\
\hline \multicolumn{2}{|c|}{$\operatorname{Max}|z|($ at period 2) } & 1.915913 & 90 & $0.02032^{* * *}$ & \multicolumn{2}{|c|}{$\operatorname{Max}|z|($ at period 2)* } & 4.81566 & 90 & 0 \\
\hline \multirow{2}{*}{\multicolumn{2}{|c|}{ Individual Tests }} & & & & Wald (Chi & quare) & 23.21851 & 4 & 0.0001 \\
\hline & & & & & \multicolumn{5}{|c|}{ Individual Tests } \\
\hline Period & Var. Ratio & Std. Error & z-Statistic & Probability & Period & Var. Ratio & Std. Error & \multicolumn{2}{|c|}{ z-Statistic Probability } \\
\hline 2 & 0.492385 & 0.264947 & -1.91591 & 0.0554 & 2 & 0.492385 & 0.105409 & -4.81566 & 0 \\
\hline 4 & 0.255857 & 0.41344 & -1.79988 & 0.0719 & 4 & 0.255857 & 0.197203 & -3.77349 & 0.0002 \\
\hline 8 & 0.138274 & 0.51187 & -1.68349 & 0.0923 & 8 & 0.138274 & 0.311805 & -2.76367 & 0.0057 \\
\hline 16 & 0.062445 & 0.582854 & -1.60856 & 0.1077 & 16 & 0.062445 & 0.46398 & -2.02068 & 0.0433 \\
\hline
\end{tabular}

$\mathrm{H}_{0}$ : Lag of Stancdard Chartered Banks is a Martingale $\quad \mathrm{H}_{\mathrm{o}}$ : First Lag of Standard Chartered Bank is Random

Heteroskedasticity robust standard error estimates $\quad$ Stnadard error estimates assume in heteroskedasticit

\begin{tabular}{lccclccc}
\hline Joint Tests & Value & df & Probability & Joint Tests & Value & df & Probability \\
\hline $\operatorname{Max}|z|$ (at period 4) & 2.09914 & 90 & $0.137^{* * *}$ & Max $|z|($ at period 4)* & 3.573821 & 90 & 0.0014 \\
\hline Individual Tests & & & Wald (Chi-square) & 23.21851 & 4 & 0.0086 \\
\cline { 6 - 8 } & & & Individual Tests & & &
\end{tabular}

Period Var. Ratio Std. Error z-Statistic Probability Period Var. Ratio Std. Error z-Statistic Probability

$\begin{array}{cccccccccc}2 & 0.642931 & 0.2165 & -1.64928 & 0.0991 & 2 & 0.642931 & 0.105409 & -3.38745 & 0.0007 \\ 4 & 0.295233 & 0.335741 & -2.09914 & 0.0358 & 4 & 0.295233 & 0.197203 & -3.57382 & 0.0004 \\ 8 & 0.132325 & 0.420322 & -2.06431 & 0.039 & 8 & 0.132325 & 0.311805 & -2.78275 & 0.0054 \\ 16 & 0.073862 & 0.503956 & -1.83774 & 0.0661 & 16 & 0.073862 & 0.46398 & -1.99507 & 0.0459\end{array}$

